\title{
¿Versus Venecia? Primera Bienal de Arquitectura de Chicago, 2015
}

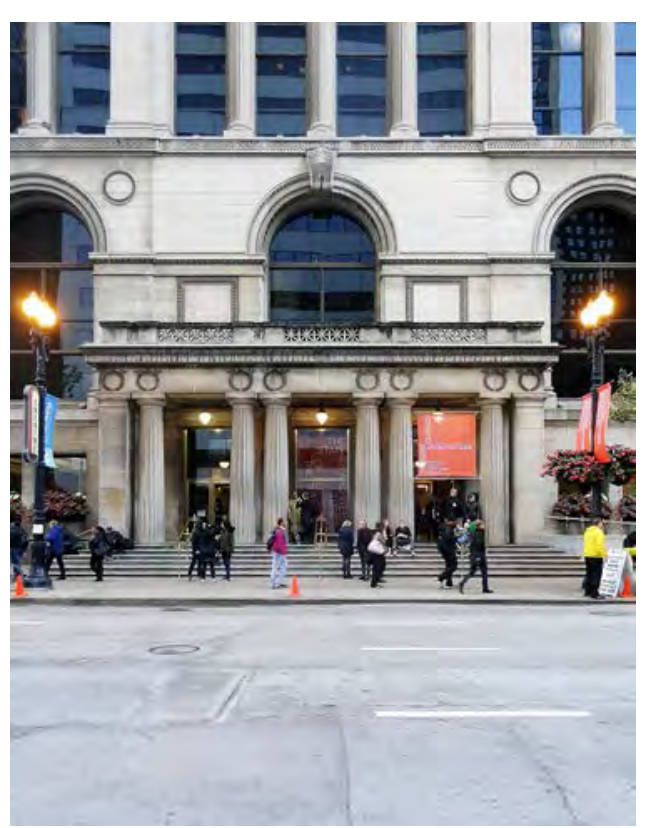

Chicago Cultural Center, Chicago, EE.uU. (c) Sebastián Paredes

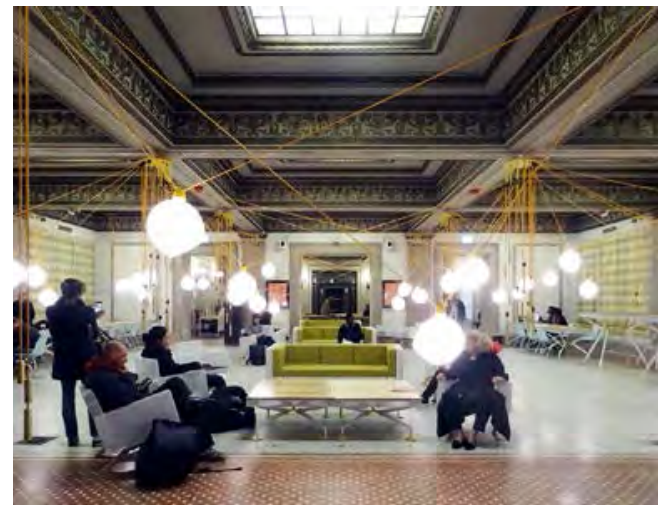

Randolph, intervención de Pedro\&Juana. c) Sebastián Paredes

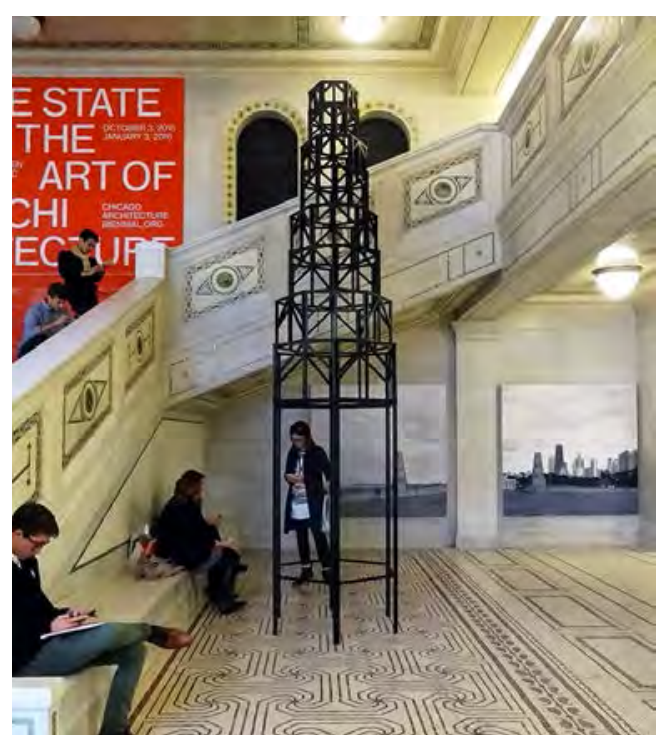

Maqueta e imágenes de Cent Pavilion, Pezo von Ellrichshausen. (c) Sebastián Paredes

para la $\mathrm{I} 4^{\mathrm{a}}$ Bienal de Arquitectura de Venecia, la ciudad de Chicago anunciaba la intención de organizar su propia Bienal de Arquitectura, el primer evento de este tipo en suelo estadounidense ${ }^{1}$. $Y$ a pesar de que podemos identificar más de treinta convocatorias ligadas a la arquitectura en ciudades como São Paulo, Lisboa, Shenzen o Rotterdam, en sus primeros comunicados de prensa el evento de Chicago parecía enfocarse sólo a su símil de Venecia, configurando su identidad a partir de las diferencias que tendría con eventos similares $y$, también, con la ciudad en que se inserta.

A fines de junio del año 20I4, el mismo mes en que Rem Koolhaas inauguró su curatoría
I KAMIN, Blair. «Chicago plans global architectural expo for 2015», 24 de junio de 2014, [disponible en $<$ http://www. chicagotribune.com/news/columnists/ct-chicago-architecturebiennial-met-0624-20140624-column.html>, consultado el $20 \mathrm{de}$ octubre de 2015].

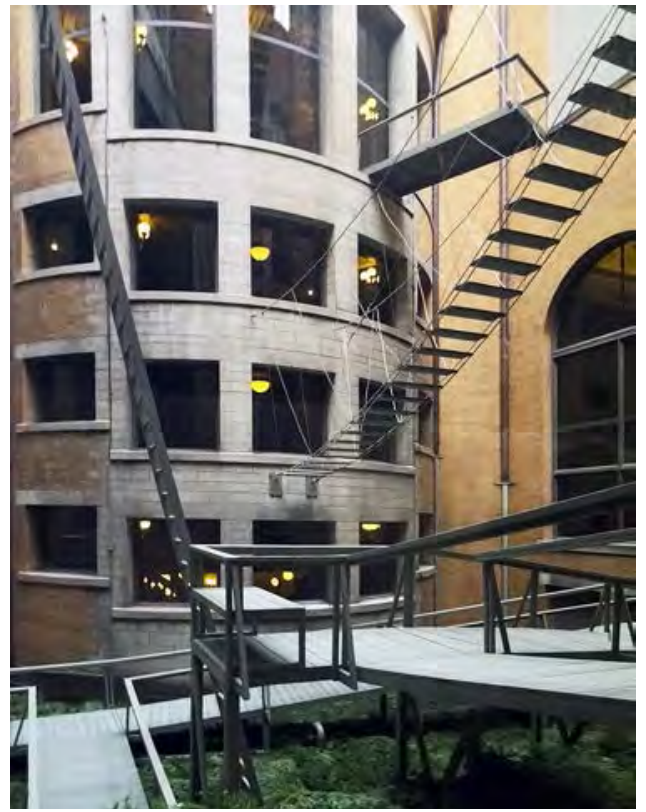

Piranesi Circus, Atelier Bow-Wow. (c) Sebastián Paredes respecto a este: entrada gratuita, a diferencia de los treinta euros que cuesta la entrada a la Bienal de Venecia; vocación internacional, pero sin distribuir a los invitados en pabellones nacionales; y la intención de ser realizada cada año impar, precisamente los años en que el foco de Venecia está puesto en la Bienal de Arte.

Esta operación cultural, que transformaría a Chicago en un nuevo destino para arquitectos, entusiastas, turistas y, eventualmente, inversionistas, se inauguró el 3 de octubre del año 2015. La bienal cuenta con un importante apoyo económico de actores privados, principalmente в (quienes siguen lidiando con las consecuencias del derrame del Deepwater Horizon ocurrido en 20I0) y la gestión de la alcaldía de Rahm Emanuel, ex jefe de Estado Mayor de Obama y alcalde de Chicago 


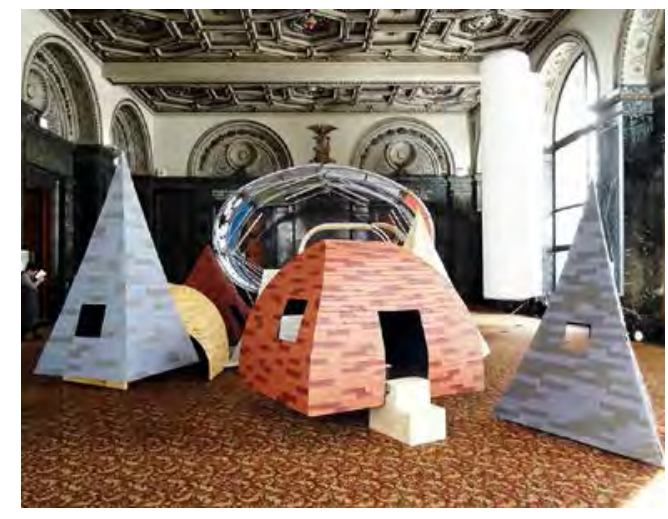

Children's Town, Maki Onishi + Yuki Hyakuda. (c) Sebastián Paredes

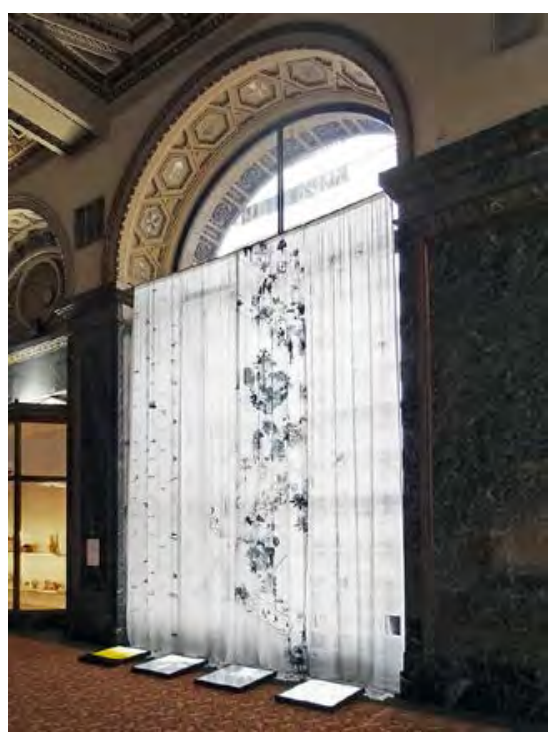

Islands, Atolls, and Other Derivative Territories, LCLA Office (c) Sebastián Paredes

desde 20Ir. La dirección artística fue asumida por Sarah Herda, directora de la Graham Foundation, y Joseph Grima, exdirector en jefe de la revista Domus y curador de distintas bienales y festivales de arquitectura y diseño (Kortrijk, Estambul y, próximamente, Matera).

El guión de las bienales pareciera desarrollarse con éxito en distintas latitudes, sin embargo, la razón por la que destaca Chicago es su cultura e historia ligada a la arquitectura y a la manera en la que se ha conformado la ciudad. El título del evento, The State of the Art of Architecture, hace referencia a esta cultura, tomando el nombre de una conferencia realizada por el arquitecto Stanley Tigerman en la misma ciudad en 1977 junto a invitados como Michael Graves, Frank Gehry, John Hedjuk,

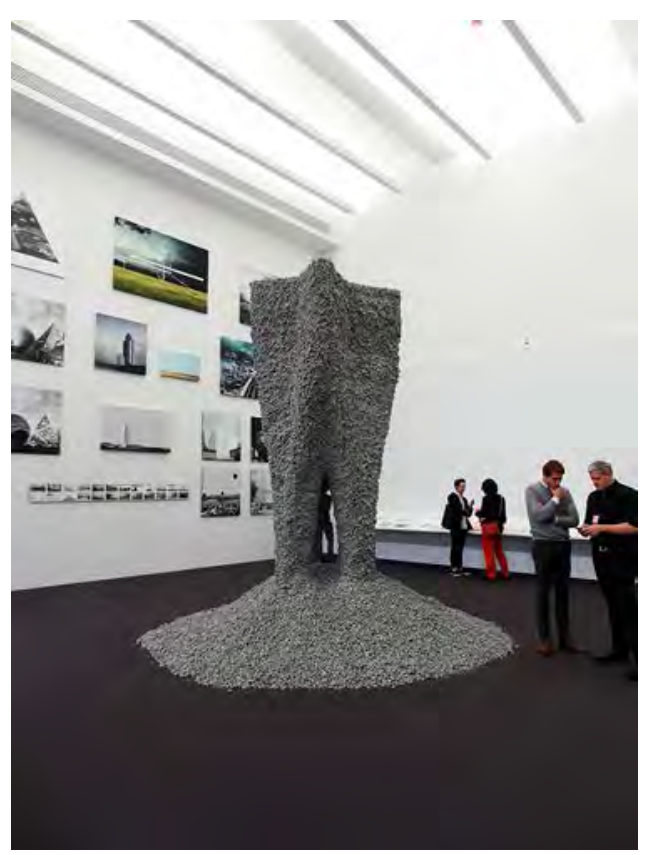

En primer plano: Rock Print, por Gramazio Kohles Research, ETH Zürich + Self-Assembly Lab, MIT. En el muro Narrative Architecture: A Manifesto, por WAI Architecture Think Tank.

(C) Sebastián Paredes

Charles Jencks, entre otros. La bienal del 2015 busca ampliar la pregunta sobre el estado de la arquitectura y también las posibles respuestas: se convoca a más de cien invitados de alrededor de treinta países, quienes usan distintos medios de representación para dar una respuesta. Así, la cacofonía se transforma en una constante en este tipo de eventos.

Prototipos a escala real, fotografías, material de archivo, instalaciones, imágenes de concursos, nuevos sistemas constructivos, maquetas, videos, investigaciones y todo el espectro de recursos de la llamada 'arquitectura de salón' se encuentran en el centro de operaciones de la bienal, el Chicago Cultural Center, un edificio de finales del siglo xıx que alguna vez fue la principal biblioteca pública de la

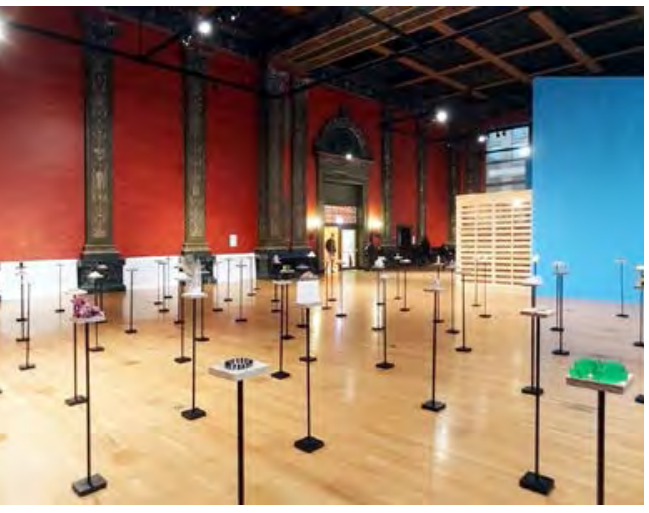

Architecture is Everywhere, Sou Fujimoto. (c) Sebastián Paredes

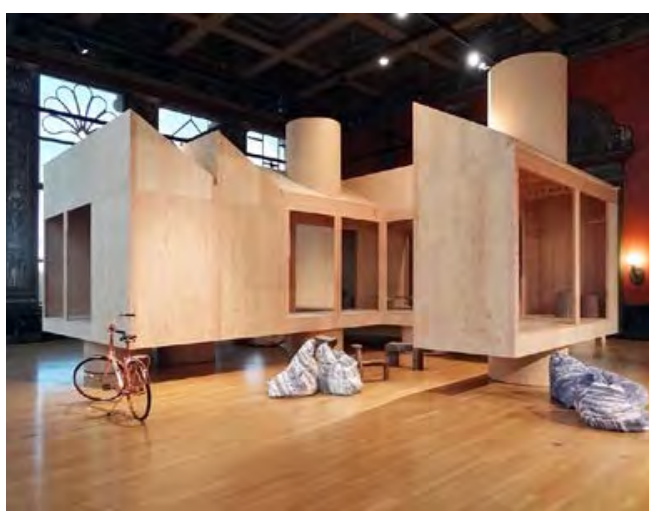

House No. 11 (Corridor House), mos Architects. (c) Sebastián Paredes ciudad. Otras instituciones asociadas al evento -la Chicago Architecture Foundation, Graham Foundation, Art Institute of Chicago y el Museum of Contemporary Art, por nombrar algunas- se encargan de realizar visitas guiadas, exposiciones y charlas que amplían el territorio de acción de la bienal hacia la ciudad.

Es en este movimiento hacia el South Side de Chicago, específicamente, donde podemos encontrar uno de los hitos de este evento. Coincidiendo con la apertura de la bienal, se inauguró el Stony lsland Arts Bank, un banco construido en 1923 y abandonado en 1980 que fue recientemente recuperado y transformado en un centro cultural por el artista local Theaster Gates. Una habilitación precisa para un espacio que albergará colecciones, archivos, talleres 


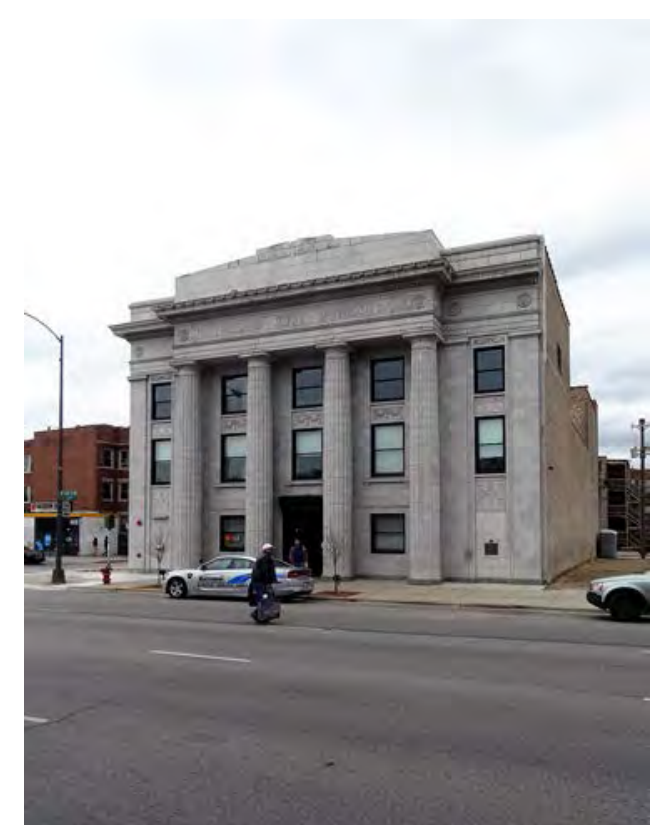

Stony Island Arts Bank, Chicago, EE.uU. C) Sebastián Paredes

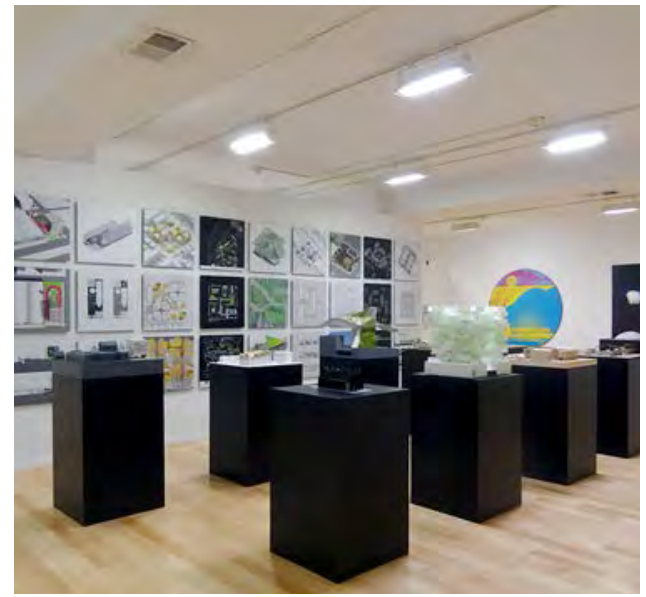

Exposición Bold: Alternative Scenarios for Chicago (c) Sebastián Paredes

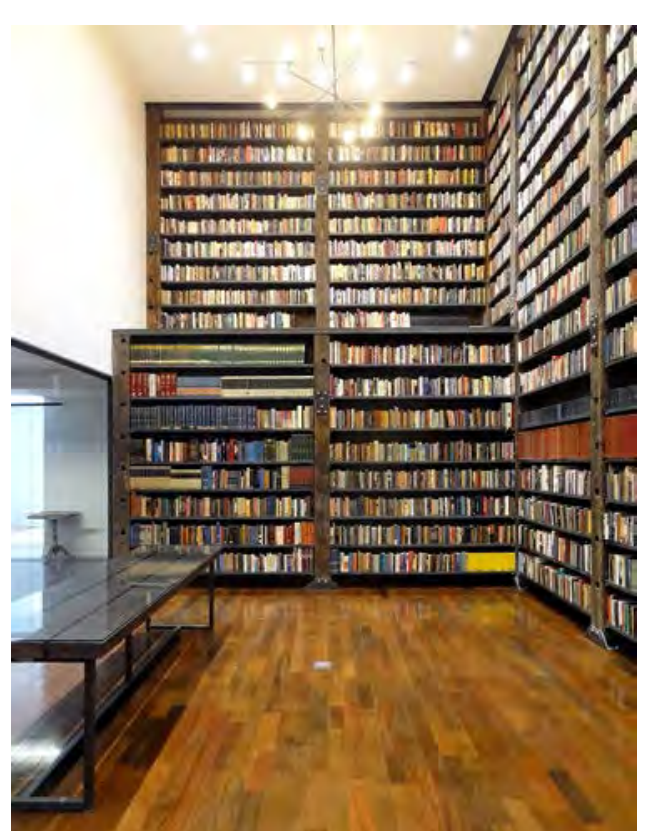

Biblioteca del Stony Island Arts Bank C Sebastián Paredes y actividades abiertas para la comunidad, haciendo referencia a los procesos de abandono de las ciudades y la reconstrucción de identidad como resistencia. Quizás esta es una de las lecciones que deberían tomar otras bienales; asumir este tipo de instancias como una oportunidad de activar nuevos espacios y celebrar la arquitectura, en vez de una circulación de figuras que, en muchos casos, se mueven como mercancías culturales.

Por una parte, The State of the Art of Architecture aspira a ser una piedra fundacional diversa en ideas, contextos, medios de representación y recursos, logrando su objetivo con creces. Por otra, el debate respecto al futuro de Chicago (que continúa después de la inauguración, cuando la prensa ha dejado de atender el evento) es quizás algo que ha pasado desapercibido para el público internacional. La bienal se ha convertido en una instancia importante para reunir a los actores locales e impulsar la acción respecto a temas que son atingentes a la ciudad. La exposición Bold: Alternative Scenarios for Chicago, las propuestas para repensar las estaciones de policía como centros comunitarios, las charlas acerca de la preservación de edificios posmodernos e incluso las visitas guiadas gratuitas a edificios icónicos dan cuenta de este objetivo más local. Es aquí donde las diferencias con Venecia se hacen evidentes y sus reales competidores se vuelven más claros.

En junio del 2015, un mes antes de que Venecia anunciara a su nuevo curador, el alcalde Rahm Emanuel inauguraba el 606 Trail $^{2}$, un parque urbano en altura sobre una estructura ferroviaria en desuso, una mejora en la ciudad que, si seguimos el caso del High

2 Trotter, Greg. «The 606 trail debuts to sunshine, happy crowds», 6 de junio de 2015, [disponible en <http:// www.chicagotribune.com/news/local/breaking/ct-606bloomingdale-trail-opening-met-20150606-story.html>, consultado el 20 de octubre de 2015].
Line, lleva asociados procesos de gentrificación e importantes flujos de capital. Mejorar la calidad de vida a través de la arquitectura ha demostrado ser un buen negocio y Chicago quiere generar esos proyectos antes que Nueva York, Londres o Sídney, ya sea con arquitectos locales o figuras internacionales. Desde esa perspectiva, una Bienal de Arquitectura puede ser una instancia servicial, crítica o neutral ante estos procesos. El éxito de estos eventos, no sólo en número de visitantes sino que en términos de proyecciones futuras, depende finalmente de los curadores y su capacidad para establecer o cuestionar agendas, más que de actuar únicamente como agentes turísticos. ARQ 


\section{I0.9K}

Tras la inauguración de la primera Bienal de Arquitectura de Chicago es necesario revisar una idea planteada por Cristopher Haw thorne ${ }^{1}$ en $L A$ Times y apoyada por muchos de los participantes: los invitados de Grima y Herda dan cuenta de un cierto cambio generacional. No vemos a ninguno de los llamados star architects y su arquitectura global. Sin embargo, que no estén presentes no significa que algunos de los invitados no repliquen sus estrategias (o vayan a replicarlas a futuro).

Uno de los termómetros de la llamada star architecture podría ser la utilización de fotografías de las caras de los arquitectos como portadas de la revista El Croquis. Quizás fue sólo un síntoma del período, pero para toda una generación significó un cambio: ya no bastaba con las obras, sino que también era necesario construir un personaje $y$, a la vez, un teatro -muchas veces un circo- global.

En el escenario de la Bienal de Chicago, dos de los invitados tenían ese estatus: Sou Fujimoto (El Croquis I5I) y Lacaton \& Vassal (El Croquis I77-I78), a quienes podríamos considerar dentro de este star system. Sin embargo, la diferencia de estos radica en los hábitos.

En su presentación en la Bienal de Arquitectura de Chicago, Architecture Is Everywhere, Sou Fujimoto declara que «architecture is found and then made», dos punch lines que podrían estar en poleras o pósteres motivacionales. La muestra se construye a partir de objetos encontrados y posteriormente transformados en escenarios para pequeñas personas de plástico (escala I: 200 aprox.). En este punto es fácil asentir: existe cierta inventiva y se abre un campo de posibilidades, pero vale la pena analizar el fenómeno. Probablemente la imagen que más se ha repetido en esta bienal corresponde a una pieza de esta muestra: un montón de papas fritas como posible arquitectura. De

I HAWTHORNE, Cristopher. «In Chicago, an ambitious biennial for architecture banishes the stars and anoints a new generation», 2015, [disponible en $<\mathrm{http} / / /$ www.latimes com/entertainment/arts/la-ca-cm-chicago-architecturebiennial-2015ıoII-column.html>, consultado el I4 de octubre de 20I5]
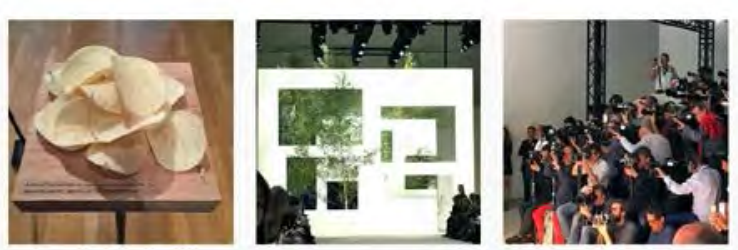

Composición hecha a partir de la búsqueda de \#soufujimoto en Instagram [Accedido el: 14 de octubre de 2015]

C) Sebastián Paredes
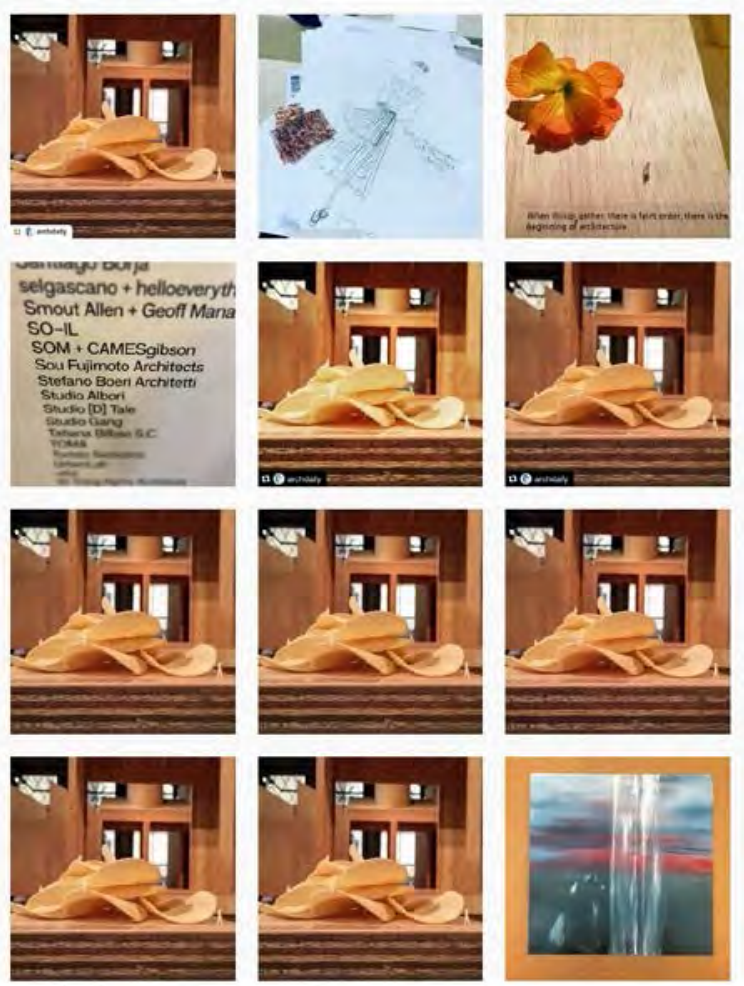

hecho, es una de las imágenes más viralizadas del evento, perfecta para la cultura del like (Io.9k en la cuenta de Instagram de Archdaily, por ejemplo ${ }^{2}$ ). Una idea de consumo masivo como su misma materialidad. Una mezcla entre ironía y sensibilidad japonesa; el oportunismo de Koolhaas con sensibilidad de Sejima.

En paralelo a los primeros días de la Bienal de Chicago, en el Paris Fashion Week la marca Akris presentaba su colección primavera/ verano 2016 basada en la arquitectura de Fujimoto. Mientras tanto, en Shanghái, el museo Power Station of Art inauguraba la exposición monográfica Sou Fujimoto: Futures of the Future. Así, se copan los medios, ámbitos culturales y espacios de poder. Creo que todos

2 El número fue revisado el I4 de octubre del 2015 y ha ido aumentando con el tiempo. hemos visto este guión interpretado por otros arquitectos, particularmente antes de la crisis económica de 2008. Ya en el contexto actual, hay que cuestionarse si estos hábitos y sus consecuencias siguen teniendo validez, especialmente por la celebrada y cacofónica generación de recambio presente en la Bienal de Chicago, para, luego, establecer diferencias claras.

En el mismo salón que se encuentra la muestra de Fujimoto, con menos parafernalia que otros participantes de la Bienal, Lacaton \& Vassal presentan una serie de videos vinculados con la transformación de 530 unidades de vivienda en Bordeaux, las cuales originalmente iban a ser demolidas. Una comprensión atingente de los alcances profesionales y los recursos económicos y sociales que dan forma a la ciudad. Sin juegos ni ironías. ARQ 